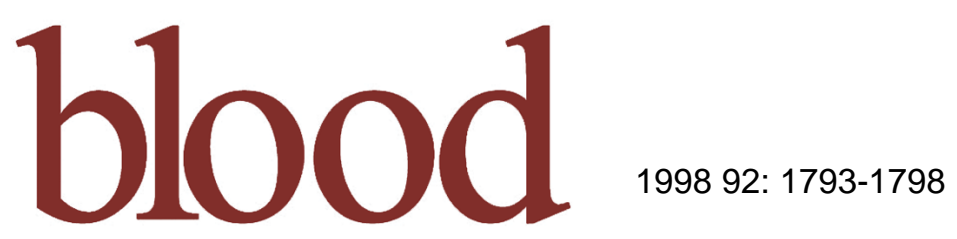

\title{
Anemia in Children With Cancer Is Associated With Decreased Erythropoietic Activity and Not With Inadequate Erythropoietin Production
}

Francis Corazza, Yves Beguin, Pierre Bergmann, Marie André, Alina Ferster, Christine Devalck, Pierre Fondu, Marc Buyse and Eric Sariban

Updated information and services can be found at:

http://bloodjournal.hematologylibrary.org/cgi/content/full/92/5/1793

Articles on similar topics may be found in the following Blood collections:

Red Cells (1178 articles)

Information about reproducing this article in parts or in its entirety may be found online at:

http://bloodjournal.hematologylibrary.org/misc/rights.dtl\#repub_requests

Information about ordering reprints may be found online at:

http://bloodjournal.hematologylibrary.org/misc/rights.dt|\#reprints

Information about subscriptions and ASH membership may be found online at:

http://bloodjournal.hematologylibrary.org/subscriptions/index.dtl

Blood (print ISSN 0006-4971, online ISSN 1528-0020), is published semimonthly by the American Society of Hematology, 1900 M St, NW, Suite 200, Washington DC 20036.

Copyright 2007 by The American Society of Hematology; all rights reserved.

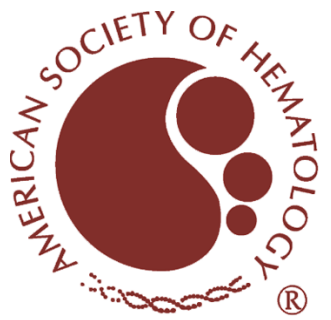




\title{
Anemia in Children With Cancer Is Associated With Decreased Erythropoietic Activity and Not With Inadequate Erythropoietin Production
}

\author{
By Francis Corazza, Yves Beguin, Pierre Bergmann, Marie André, Alina Ferster, Christine Devalck, \\ Pierre Fondu, Marc Buyse, and Eric Sariban
}

\begin{abstract}
A defect in erythropoietin (EPO) production has been advocated as being the main cause of anemia presented at time of diagnosis or during treatment by adults with solid tumors. On the basis of this defect, anemic cancer patients, both adults and children, have been treated with recombinant human EPO (rHuEPO). To further elucidate the pathophysiology of anemia in children with cancer, we measured senum soluble transferin receptor (STfR), a quantitative marker of enythropoiesis, and serum EPO at time of diagnosis and during chemotherapy in children suffering from solid tumor or leukemia. We determined serum EPO in 111 children (55 leukemia, 56 solid tumors) at time of diagnosis. In the last 44 patients ( 23 leukemia and 21 solid tumors), sTfR levels were also measured. Serum EPO together with STfR levels were also determined in 60 children receiving chemotherapy (29
\end{abstract}

$\mathbf{T}$

HE LEVEL OF BONE MARROW erythropoietic activity depends on the number of erythroid precursors involved in proliferation and differentiation. In the human body, $80 \%$ of the transferrin receptors are located in the erythroid marrow. Because a constant relationship exists between membrane receptors and serum receptors, determination of serum soluble transferrin receptors (sTfR) has been used to assess bone marrow erythropoietic activity. ${ }^{1}$ The late stages of erythropoiesis are mainly dependent on erythropoietin (EPO), which induces proliferation and terminal differentiation of committed red blood cell progenitors. In the presence of a normal marrow stem cell reserve, erythropoiesis increases in proportion to the degree of anemia through an exponential increase of EPO. Thus, simultaneous determination of sTfR levels (erythroid marrow activity) and serum EPO levels (erythropoietin stimulation) has been used to investigate the pathophysiology of red blood cell disorders in different clinical settings.

Several studies of patients with hematologic malignancies have described EPO levels appropriate for the degree of anemia. ${ }^{2-4}$ In contrast, in patients suffering from solid malignancies, the observed defect in EPO production has been advocated as being the main cause of anemia presented by these patients either at time of diagnosis or during treatment. ${ }^{5}$ This defect has been put forward as a rational basis for treating the anemia of cancer patients, both adults and children, with recombinant human EPO (rHuEPO).

In the present study, we investigated the pathophysiology of anemia presented at time of diagnosis and during treatment by children suffering from either solid tumors or hematologic malignancies. The adequacy of EPO secretion in response to anemia and the total erythropoietic activity was assessed by determination of serum EPO and sTfR levels, respectively. Our data indicate that the anemia presented by children with cancer is due to defective erythroid progenitor proliferation and not to inappropriate EPO secretion.

\section{MATERIALS AND METHODS}

Patient and control populations. We determined serum EPO level at time of diagnosis in 111 children admitted for leukemia $(\mathrm{n}=55)$ or a solid tumor $(\mathrm{n}=56)$. Diagnoses were: acute lymphoblastic leukemia leukemia, 31 solid tumors). These results were compared with those obtained from appropriate control groups. In all patients, we found a highly significant correlation between the logarithm of EPO (log[EPO]) and the hemoglobin (Hb) level. In all subsets of patients, sTfR levels were inappropriately low for the degree of anemia. Neither leukemic nor solid tumor groups showed a significant inverse relationship between log(sTfR) and the $\mathrm{Hb}$ level as would be expected in anemic patients with appropriate marrow response. Thus, in children with cancer, anemia is associated with a decreased total bone marrow erythropoietic activity which, in contrast to what has been reported in anemic cancer adults, is not related to defective EPO production.

(1) 1998 by The American Society of Hematology.

(50), acute myeloid leukemia (5), neuroblastoma (13), brain tumor (10), nephroblastoma (9), soft tissue sarcoma (6), non-Hodgkin's lymphoma (5), osteosarcoma (4), germinal tumor (4), Hodgkin's disease (3), and primitive neuroectodermic tumor (2). Among the 56 patients with a solid tumor, 6 had bone marrow involvement by malignant cells. There were 73 boys and 38 girls. The mean age was $5.5 \pm 3.2$ years (range, 1 to 15 ) in the leukemic group and $6.3 \pm 4.8$ years (range, 0.2 to 17 ) in the group with solid tumors. Blood samples at time of diagnosis were obtained before any treatment or transfusion. The sera were kept frozen until EPO measurement. Hemoglobin $(\mathrm{Hb})$, serum creatinine, and serum albumin levels were measured concurrently. Levels of serum sTfR were also measured in the last 44 patients, 23 with leukemia and 19 with a solid tumor (including 2 with bone marrow involvement). These 44 patients were white, except for 1 African subject. The study was approved by the institutional review board.

Among the 111 patients, 88 (51 with leukemia and 37 with a solid tumor) were considered anemic as defined by an $\mathrm{Hb}$ level more than two standard deviation (SD) below the normal mean value for age. ${ }^{6}$ No patient had hypoxemia. One patient with acute myeloid leukemia was excluded because of concomitant acute renal failure; all other patients had normal renal function.

We determined serum EPO together with sTfR in 60 chemotherapytreated children including 29 leukemic and 31 solid tumor patients. The

From the Laboratory of Hematology and of Clinical Chemistry, Brugmann University Hospital, Brussels; the Department of Hematology, University of Liège; Hematology-Oncology Unit, Hôpital Universitaire des Enfants, Brussels; and the International Institute for Drug Development, Brussels, Belgium.

Submitted March 5, 1998; accepted April 28, 1998.

Supported in part by Grants No. 3.4555.91, 7.4511.93, 3.4621.94, and 7.4552.95 from the Fond National de la Recherche Scientifique (FNRS), Belgium. Y.B. is a Senior Research Associate of the FNRS, Belgium.

Address reprint requests to Francis Corazza, MD, Laboratory of Hematology, Brugmann University Hospital, 4 Place Van Gehuchten, B-1020 Brussels, Belgium.

The publication costs of this article were defrayed in part by page charge payment. This article must therefore be hereby marked "advertisement" in accordance with 18 U.S.C. section 1734 solely to indicate this fact.

(1) 1998 by The American Society of Hematology.

0006-4971/98/9205-0027\$3.00/0 
median duration of chemotherapy at time of study was 2 months (range, 1 to 4 ) for the leukemic group and 4 months (range, 1 to 11) for the solid tumor group. All leukemic patients were in complete remission as assessed by bone marrow microscopic evaluation. Among the 31 solid tumor patients, 6 had been exposed to cisplatin for a median time of 3 months (range, 1 to 6 ).

In leukemic patients, serum EPO and sTfR were also measured later during the treatment: at the end of intensive treatment $(n=24$, median duration of treatment, 4.5 months; range, 4 to 6 ) and during maintenance chemotherapy $(\mathrm{n}=15$, median time of treatment, 9 months; range, 7 to 12 ).

The reference EPO curve was constructed using data obtained in 23 children, 17 boys and 6 girls, with iron deficiency anemia (17) or sickle cell disease (6), two conditions where EPO production has been shown to be appropriate to the degree of anemia. ${ }^{5,7}$ Control children had normal renal function (creatinine: $0.5 \pm 0.17 \mathrm{mg} / \mathrm{dL}$ ), no inflammation, and a good nutritional status (observed/optimal weight ratio: $92.3 \pm 13$; serum albumin: $4.3 \pm 0.4 \mathrm{~g} / \mathrm{dL}$ ).

Patients with erythroid hypoplasia have been reported to have a higher EPO production in response to anemia as compared with patients with nonhypoplastic anemia. ${ }^{8}$ Accordingly, to compare leukemic patients with control patients with a similar erythroid hypoplasia, we determined serum EPO levels in 10 anemic patients with aplastic anemia $(n=9)$ or Blackfan-Diamond anemia $(n=1)$. The mean age in this group was $11 \pm 7$ years (range, 1 to 18 ).

To construct the reference sTfR curve evaluating the erythropoietic response to anemia, samples were obtained from 18 patients with hemolytic anemia and 18 with dyserythropoietic anemia. Patients with iron deficiency were excluded, as sTfR levels are inappropriately increased in this condition. ${ }^{9}$

EPO and sTfR immunoassays. Immunoreactive EPO levels were measured by a commercially available immunoradiometric assay ( ${ }^{125} \mathrm{I}-$ EPO Coat RIA, Bio-Mérieux, Marcy L'Etoile, Lyon, France) that uses two different monoclonal antibodies raised against different epitopes of rHuEPO. The range of normal values in 26 nonanemic healthy adults was 0.9 to $8.5 \mathrm{mU} / \mathrm{mL}$ (mean $\pm \mathrm{SD}, 4.7 \pm 1.9$ ). ${ }^{10}$ The interassay coefficient of variation ranged from $4 \%$ to $12 \%$ when EPO concentration was 40 and $4 \mathrm{mU} / \mathrm{mL}$, respectively. There was no influence of sex or age on the results.

An enzyme-linked immunosorbent assay based on TfR polyclonal antibodies was used to measure sTfR as previously published. ${ }^{1}$ Each sample was run in triplicate. The interassay coefficient of variation was $7.2 \%$. With this assay, mean sTfR in 150 iron replete normal subjects was $5,000 \pm 1,050 \mu \mathrm{g} / \mathrm{L}($ mean $\pm \mathrm{SD})$. There was no influence of sex or age on the results.

Hemoglobin levels were determined using Bayer $\mathrm{H} 2$ or $\mathrm{H} 3$ automated hematology analyzers (Bayer Diagnostics, Tarrytown, NY). The other biologic parameters were measured by standard laboratory methods.

Statistical analysis. Differences between groups for mean biologic values were tested for statistical significance using the Student's $t$-test. The correlation coefficients between $\log (\mathrm{EPO})$ or $\log (\mathrm{sTfR})$ and $\mathrm{Hb}$ levels were computed in least squares regression equations. The slopes and y-intercepts of the regression lines were tested for equality between groups by Student's $t$-test. Furthermore, the adequacy of EPO and sTfR levels in relation to the degree of anemia was evaluated individually by computing the ratio between the logarithm of the observed value and the logarithm of the expected result [O/E $\log (\mathrm{EPO})$ or $\log (\mathrm{sTfR})$ ratios] according to the regression line constructed with the control group. The homogeneity of variance for these parameters among the various groups was tested by $\mathrm{F}$ test. All biologic values are reported as mean \pm SD.

\section{RESULTS}

Adequate EPO response at diagnosis in anemic children suffering from leukemia or solid tumor. Serum proteins, albumin, and creatinine levels in patients at diagnosis were normal and not different from those in the control group. The mean $\mathrm{Hb}$ level was not significantly different in patients with malignancy as compared with control anemic patients. Mean EPO level was similar in leukemic patients and in patients with solid tumors as compared with control group. When $\log (\mathrm{EPO})$ was plotted as a function of $\mathrm{Hb}$, a significant inverse linear relationship was found (Fig 1A and C) with equivalent coefficient of correlation in the leukemic, solid tumor, and control groups (Table 1). The slope and the y-intercept of the three regression lines was not significantly different. Most patients (73\% of patients with leukemia and $86 \%$ of those with solid tumors) fell within $95 \%$ confidence intervals of control subjects; in only $5 \%$ ( 3 of 55) of leukemic patients and 14\% ( 8 of 56) of patients with solid tumor was a blunted EPO response observed (Fig 1A and C). As compared with anemic controls, the mean $\mathrm{O} / \mathrm{E} \log (\mathrm{EPO})$ ratio was not different in solid tumor patients and was even significantly elevated in leukemic patients (Table 1). Variance of this ratio was higher in both patient groups than in controls. In addition, the equations of the regression lines for $\log (\mathrm{EPO})$, as well as the mean $\mathrm{O} / \mathrm{E}$ $\log (\mathrm{EPO})$ ratios, were not different when leukemic patients at time of diagnosis were compared with patients with aplastic anemia (Table 1).

Decreased erythropoiesis as measured by sTfR levels in anemic cancer children at time of diagnosis. In both groups of cancer patients evaluated at time of diagnosis, sTfR levels were significantly lower than in the control group $(3,537 \pm 2,623$ $\mu \mathrm{g} / \mathrm{L}, 5,923 \pm 3,044 \mu \mathrm{g} / \mathrm{L}$ and $24,490 \pm 16,130 \mu \mathrm{g} / \mathrm{L}$ in leukemic, solid tumor, and control groups, respectively). In addition, we did not observe the inverse relationship between sTfR and $\mathrm{Hb}$ levels that was obtained in control anemic subjects with adequate marrow function (Fig $2 \mathrm{~A}$ and $\mathrm{C}$ ). The regression equations for the leukemic and solid tumor groups were respectively: $\log (\mathrm{sTfR})=3.454+(0.004 \mathrm{Hb}), r=.04, P>$ .05 ; and $\log (\mathrm{sTfR})=4.097-(0.035 \mathrm{Hb}), r=-.379, P>.05$. Solid tumor patients with $(n=2)$ or without $(n=19)$ bone marrow infiltration had similar sTfR/Hb relationships. Eightyseven percent of leukemic patients and $48 \%$ of solid tumor patients had sTfR values well below the expected range computed from the control group; therefore, the O/E $\log (\mathrm{sTfR})$ ratios were significantly reduced in both groups of patients as compared with controls $(0.42 \pm 0.13,0.86 \pm 0.06$, and $1.00 \pm$ 0.04 in leukemic, solid tumor, and control groups, respectively).

Adequate EPO response in anemic cancer children exposed to chemotherapy. To explore whether the pathophysiology of anemia observed during treatment was similar to the one observed at time of diagnosis, EPO and sTfR measurements were performed in patients treated by intensive chemotherapy. Both in leukemic and solid tumor patients, the inverse relationship between $\log (\mathrm{EPO})$ and $\mathrm{Hb}$ was conserved and was not different from the one observed at time of diagnosis or in the control group (Fig 1B and D and Table 1). In addition, leukemic patients all along their treatment retained an adequate EPO 


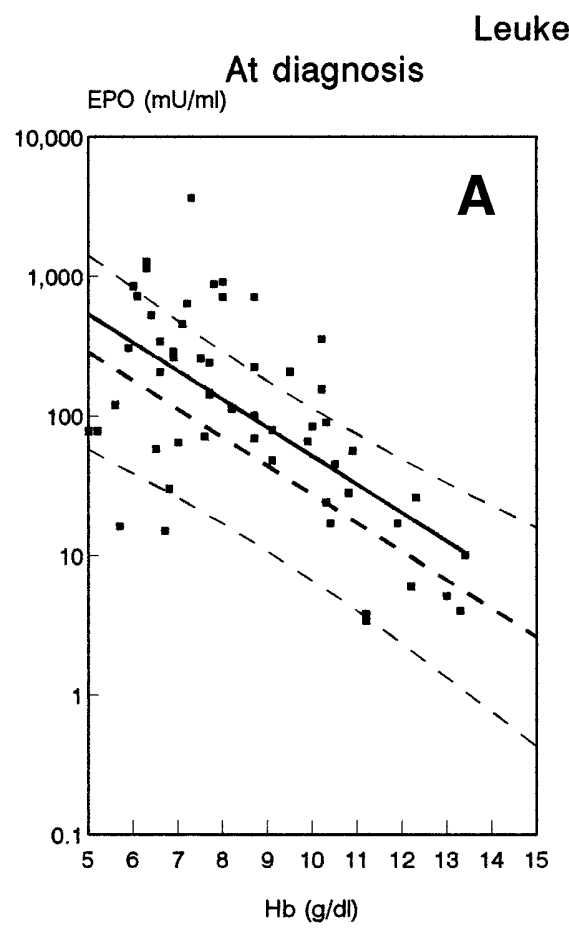

\section{patients}

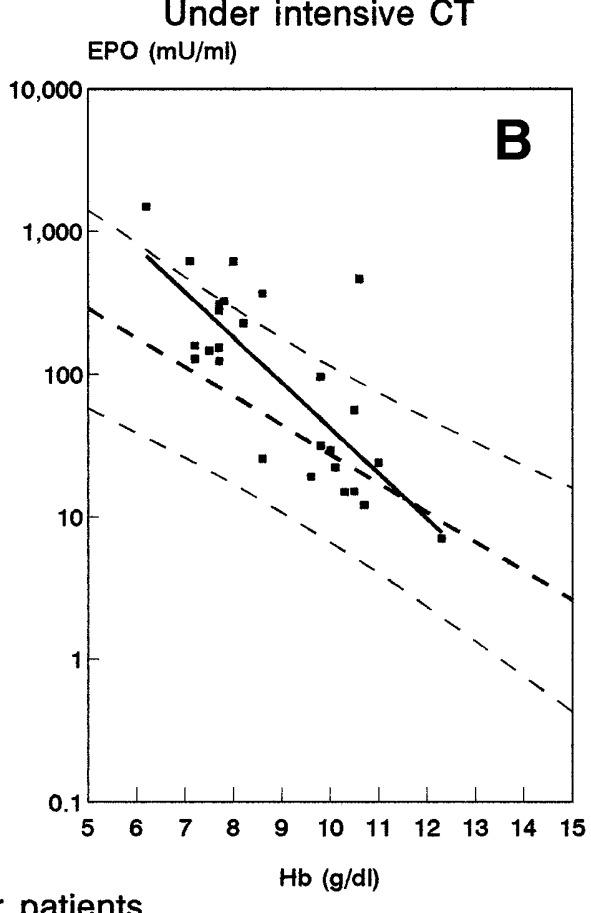

Solid tumor patients

Fig 1. Relation of the serum EPO to Hb levels in patients with leukemia studied at time of diagnosis, $n=55$ (A) or during intensive chemotherapy (CT), $n=29$ (B) and in patients with solid tumor at diagnosis, $n=\mathbf{5 6}(\mathrm{C})$, or during intensive CT, $\mathbf{n}=31$ (D). Solid lines represent the regression lines computed in each group of patients. Dashed lines depict the regression line and the $95 \%$ confidence limits of the control group. In graph (D), solid triangles represent patients receiving cisplatin $(n=6)$.
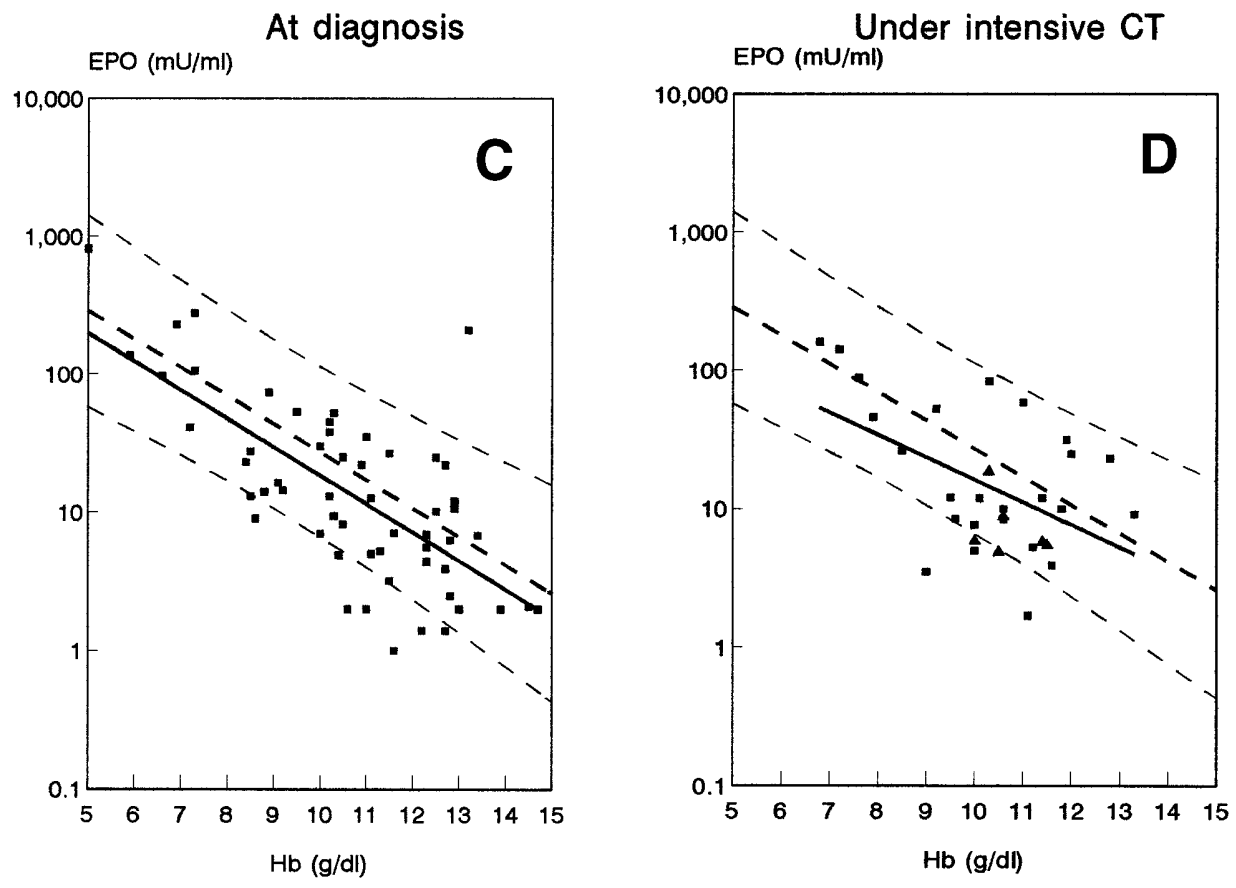

response to the degree of anemia as indicated by $\mathrm{O} / \mathrm{E} \log (\mathrm{EPO})$ ratio values close to 1 except in the early phase of intensive chemotherapy where this ratio was even elevated (Table 1). No leukemic patients presented a blunted EPO response as defined by an EPO level below the lower limit of the $95 \%$ confidence interval of the control group (Fig 1B). Only 3 of 25 patients with solid tumors not exposed to cisplatin did present a blunted EPO response (Fig 1D); the 6 patients treated by cisplatin had a significant lower $\mathrm{O} / \mathrm{E} \log (\mathrm{EPO})$ ratio as compared with the other patients (Table 1).

Decreased erythropoiesis in anemic cancer children exposed to chemotherapy. In most treated patients (90\% of leukemic patients and $69 \%$ of patients with solid tumors), erythropoietic activity as assessed by STfR level was inappropriately low for the degree of anemia (Fig 2B and D). Solid tumor patients did not show the expected inverse relationship between sTfR and 
Table 1. EPO Response to Anemia in Patients According to Time of Treatment

\begin{tabular}{|c|c|c|c|c|c|c|c|}
\hline $\begin{array}{l}\text { Patient Group } \\
\text { (no.) }\end{array}$ & $\begin{array}{l}\text { Median Duration } \\
\text { of Treatment } \\
\text { in Months } \\
\text { Mean (range) }\end{array}$ & $\mathrm{Hb} g / \mathrm{dL}$ & Regression Line Equation & $\begin{array}{c}\text { Coefficient } \\
\text { of Correlation } \\
(r)\end{array}$ & $\begin{array}{c}P \text { Value of } \\
\text { Regression }\end{array}$ & $\begin{array}{c}\text { O/E log (EPO) Ratio } \\
\text { Mean } \pm \text { SD }\end{array}$ & $\begin{array}{l}P \text { Value } \\
\text { Versus } \\
\text { Controls }\end{array}$ \\
\hline Controls (23) & & $9.1 \pm 1.5$ & $\log (E P O)=3.48-0.20 \mathrm{Hb}$ & -0.73 & $<.001$ & $1.00 \pm 0.18$ & - \\
\hline Aplastic anemia (10) & & $7.4 \pm 1.4$ & $\log (E P O)=5.05-0.33 \mathrm{Hb}$ & -0.73 & $<.01$ & $1.33 \pm 0.23$ & $<.001$ \\
\hline \multicolumn{8}{|l|}{ Leukemic patients } \\
\hline At diagnosis (55) & & $8.6 \pm 2.2$ & $\log (E P O)=3.74-0.20 \mathrm{Hb}$ & -0.63 & $<.001$ & $1.21 \pm 0.33$ & $<.0001$ \\
\hline During CT, early (29) & $2(1-4)$ & $8.9 \pm 1.6$ & $\log (E P O)=4.80-0.32 \mathrm{Hb}$ & -0.78 & $<.001$ & $1.22 \pm 0.29$ & $<.01$ \\
\hline During CT, late (24) & $5(4-6)$ & $10.2 \pm 1.9$ & $\log (E P O)=4.25-0.27 \mathrm{Hb}$ & -0.74 & $<.001$ & $1.07 \pm 0.37$ & NS \\
\hline Maintenance CT (15) & $9(7-12)$ & $11.3 \pm 1.0$ & $\log (E P O)=2.72-0.13 \mathrm{Hb}$ & -0.33 & $<.01$ & $1.10 \pm 0.30$ & NS \\
\hline \multicolumn{8}{|l|}{ Solid tumor patients } \\
\hline At diagnosis (56) & & $10.7 \pm 2.2$ & $\log (E P O)=3.32-0.21 \mathrm{Hb}$ & -0.70 & $<.001$ & $0.90 \pm 0.47$ & NS \\
\hline During CT (31) & $4(1-11)$ & $10.3 \pm 1.6$ & $\log (E P O)=2.72-0.15 \mathrm{Hb}$ & -0.47 & $<.001$ & $0.89 \pm 0.37$ & NS \\
\hline CT with cisplatin (6) & $3(1-6)$ & $10.6 \pm 0.6$ & $\log (E P O)=2.28-0.13 \mathrm{Hb}$ & -0.37 & $<.01$ & $0.70 \pm 0.15$ & $<.05$ \\
\hline
\end{tabular}

Abbreviations: $\mathrm{CT}$, chemotherapy; NS, not significant.

Hb: $\log (\mathrm{sTfR})=3.329+(0.026 \mathrm{Hb}), r=.217, P>.05($ Fig 2D). In leukemic patients, there was even a positive correlation between sTfR and $\mathrm{Hb}: \log (\mathrm{sTfR})=2.649+(0.084 \mathrm{Hb}), r=$ $.602, P<.008$ (Fig 2B). Altogether, these results indicate that the anemia was associated with a lack of erythropoietic progenitors and not with EPO deficiency.

\section{DISCUSSION}

The EPO response to anemia in patients with cancer has been a matter of debate. Among adults with solid tumors, inadequate EPO response to the anemia has been reported in patients at time of diagnosis or during treatment, ${ }^{5,11}$ but this has not been a constant finding. ${ }^{12,13}$ An EPO defect has been well documented in patients with multiple myeloma, even in the absence of renal failure. ${ }^{14}$ However, in other hematologic malignancies, including chronic lymphocytic leukemia, ${ }^{4}$ Hodgkin's disease, ${ }^{3}$ and acute leukemia, ${ }^{2}$ most of the patients showed an adequate EPO response to anemia.

Whether these findings in adults also apply to children has not been well-demonstrated. In the present study, a significant inverse relationship between $\log (\mathrm{EPO})$ and $\mathrm{Hb}$ was observed, either at time of diagnosis or during chemotherapy, in children suffering from leukemia or solid tumors. In only $10 \%$ (11 of 111) of newly diagnosed cancer patients and 5\% (3 of 54) of treated patients not exposed to cisplatin was a blunted EPO response observed. Individual EPO response to anemia, analyzed by computing the ratio between observed and expected $\log (\mathrm{EPO})$, was also appropriate. Similar results were found when leukemic patients at time of diagnosis were compared with patients with erythroid hypoplasia secondary to aplastic anemia, a group of patients known to have the highest EPO levels in response to anemia. ${ }^{8}$ Altogether, these results suggest that, in marked contrast to what has been observed in adults, ${ }^{5}$ EPO production in response to anemia is undamaged in most children with malignancy-associated anemia.

Leukemic patients evaluated had massive blastic infiltration of the bone marrow explaining the absence of erythroid proliferation. In contrast, most children with solid tumors presented without bone marrow metastases. However, both populations presented erythroid hypoplastic marrow as indi- cated by low sTfR levels; thus, it is possible that the defect in erythroid progenitor activity observed in these patients is secondary to the presence of soluble inhibitory factors associated with malignancy.

Increased production of several cytokines, including interleukin-1 (IL-1), ${ }^{15}$ tumor necrosis factor- $\alpha$ (TNF- $\left.\alpha\right),{ }^{16}$ interferon- $\gamma$ $(\mathrm{IFN}-\gamma),{ }^{17}$ and transforming growth factor- $\beta$ (TGF- $\left.\beta\right)^{18}$ has been demonstrated in a variety of cancers. These cytokines affect erythropoiesis through different pathways. ${ }^{19}$ In vitro, they inhibit the growth of erythropoietic progenitors, decrease the sensitivity of erythropoietic cells to the trophic effect of EPO, and suppress the hypoxia-dependent EPO production. ${ }^{20-22}$ In vivo, these cytokines have also been reported to suppress erythropoiesis. ${ }^{23-25}$ In addition, hematopoietically active chemokines such as macrophage inflammatory protein-1 $\alpha$ have been involved in the inhibition of erythropoiesis both in vitro ${ }^{26}$ and in vivo. ${ }^{27}$ It remains to be determined if one or more of these factors are involved in the etiology of cancer-associated anemia.

In contrast to results published in adults, ${ }^{5} \mathrm{EPO}$ response in children under treatment for leukemia or a solid tumor was also adequate for the degree of anemia except in those patients receiving cisplatin. This suggests that the anemia presented by these children was mainly due to the direct myelotoxic effect of chemotherapy and that inadequate EPO response plays a very minor role, if any, in the etiology of the anemia.

Treatment with $\mathrm{rHuEPO}$ has been partially effective in the treatment of the anemia of cancer patients receiving or not receiving chemotherapy. ${ }^{28,29}$ However, only a minority of the patients show a complete response, and the doses required are considerably larger than those used in renal failure patients. In contrast to this latter population, many cancer patients fail to respond to high doses of rHuEPO. Although algorithms have been proposed, there is no convenient and reliable predictor of response to rHuEPO in adults. ${ }^{30}$ The small studies conducted in children with solid tumors show a minor effectiveness of rHuEPO with only a small reduction in transfusion needs. ${ }^{31,32}$ Although rHuEPO use has not been associated with important toxicity in adult cancer patients, the risks of rHuEPO treatment in children has yet to be defined.

In conclusion, our data indicate that the mechanisms of 


\section{Leukemic patients}

At diagnosis

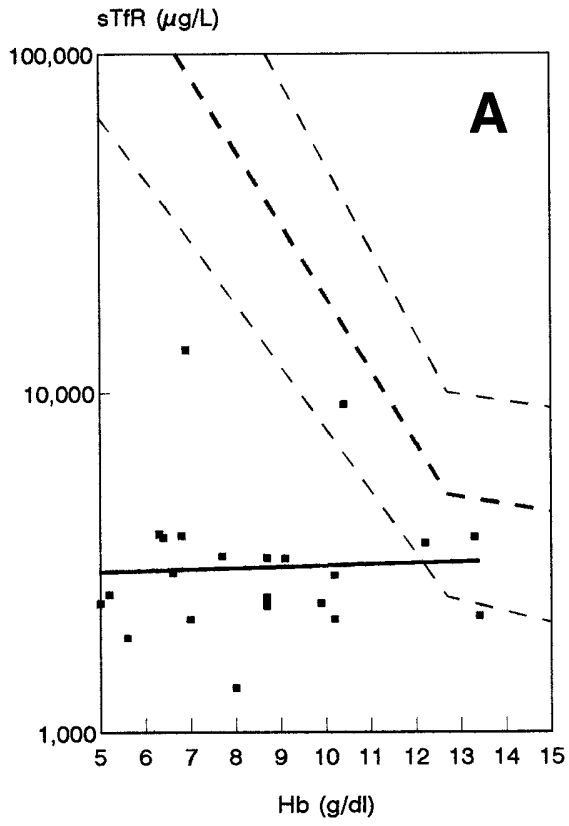

Under intensive CT sTfR $(\mu \mathrm{g} / \mathrm{L})$

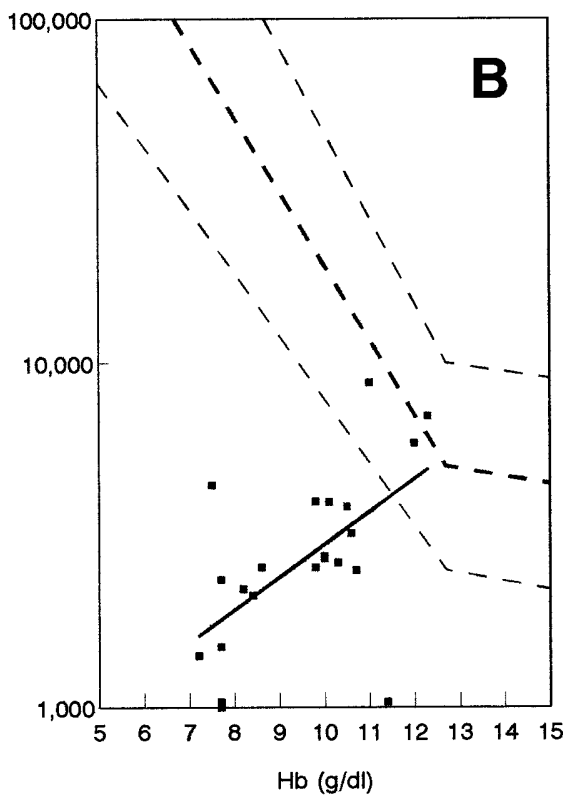

Fig 2. Relation of senum sTfR to Hb levels in patients with leukemia studied at time of diagnosis, $n=21$ (A) or during intensive $C T, n=23$ (B) and in patients with solid tumor at diagnosis, $n=21(C)$, or during intensive $C T, \mathbf{n}=\mathbf{3 0}$ (D). Solid lines represent the regression lines computed in each group of patients. Dashed lines depict the regression line and the $95 \%$ confidence limits of the control population showing an appropriate stimulation of enythropoiesis by the anemia.

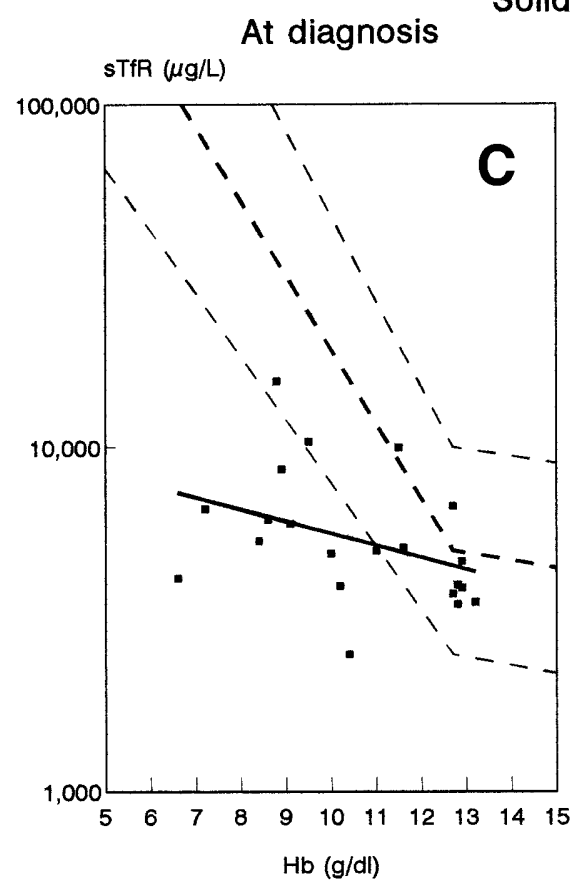

Solid tumor patients

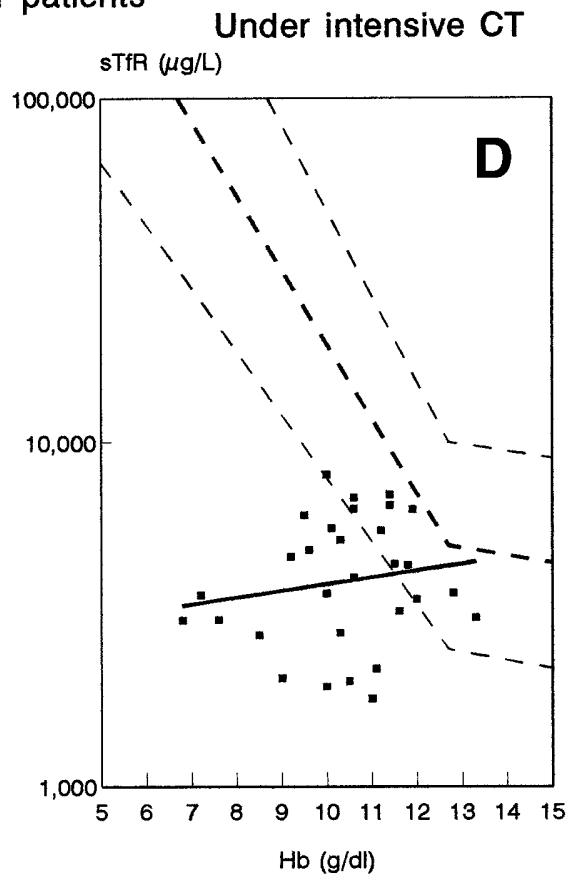

cancer anemia in children differ from the ones reported in adults. In our study, anemia was associated with early defective erythropoiesis and not with inadequate EPO production. Thus, treatment of anemic cancer children with rHuEPO might be of limited efficacy because mechanisms others than a defective EPO response negatively control marrow erythropoietic activity. Administration of growth factors known to promote the growth of more primitive cells might be of interest. In addition, agents such as antiinflammatory compounds ${ }^{33}$ and monoclonal antibodies capable of reversing the effects of inhibitory cytokines might also be of potential clinical use.

\section{ACKNOWLEDGMENT}

The authors thank Jean-Marie Giot for his expert technical assistance. 


\section{REFERENCES}

1. Beguin Y, Clemons G, Pootrakul P, Fillet G: Quantitative assessment of erythropoiesis and functional classification of anemia based on measurements of serum transferrin receptor and erythropoietin. Blood $81: 1067,1993$

2. Hellebostad M, Marstrander J, Slrdhl SH, Cotes M, Refsum HE: Serum immunoreactive erythropoietin in children with acute leukemia at various stages of disease and the effects of treatment. Eur J Haematol $44: 159,1990$

3. Pohl C, Schobert I, Moter A, Woll EM, Schwonzen M, Hiersche A, Diehl V: Serum erythropoietin levels in patients with Hodgkin's lymphoma at the time of diagnosis. Ann Oncol 3:172, 1992

4. Beguin Y, Lampertz S, Fillet G: Serum erythropoietin in chronic lymphocytic leukemia. Br J Hematol 93:154, 1996

5. Miller CB, Jones RJ, Piantadosi S, Abeloff MD, Spivak JL: Decreased erythropoietin response in patients with the anemia of cancer. N Engl J Med 322:1689, 1990

6. Nathan DG, Orkin SH: Nathan and Oski's Hematology of Infancy and Childhood (ed 5). Philadelphia, PA, Saunders, 1998, Appendix 11

7. Erslev AJ, Wilson J, Caro J: Erythropoietin titers in anemic, non uremic patients. J Lab Clin Med 109:429, 1987

8. Schrezenmeier H, Noé G, Raghavachar A, Rich IN, Heimpel H, Kubanek B: Serum erythropoietin and serum transferrin receptor levels in aplastic anemia. Br J Hematol 88:286, 1994

9. Punnonen K, Irjala K, Rajamaki A: Iron-deficiency anemia is associated with high concentrations of transferrin receptor in serum. Clin Chem 40:774, 1994

10. André M, Ferster A, Toppet M, Fondu P, Dratwa M, Bergmann P: Performance of an immunoradiometric assay of erythropoietin and results for specimens from anemic and polycythemic patients. Clin Chem 38:758, 1992

11. Wood PA, Hrushesky WJM: Cisplatin-associated anemia: An erythropoietin deficiency syndrome. J Clin Invest 95:1650, 1995

12. Smith DH, Goldwasser E, Vokes EE: Serum immunoerythropoietin levels in patients with cancer receiving cisplatin-based chemotherapy. Cancer 68:1101, 1991

13. Urabe A, Mitani K, Yoshinaga K, lki S, Yagisawa M, Ohbayashi Y, Takaku F: Serum erythropoietin titers in hematological malignancies and related diseases. Int J Cell Cloning 10:333, 1992

14. Beguin Y, Yerna M, Loo M, Weber M, Fillet G: Erythropoiesis in multiple myeloma: Defective red cell production due to inappropriate erythropoietin production. Br J Haematol 82:648, 1992

15. Rodriguez-Cimadevilla JC, Beauchemin V, Villeneuve L, Letendre F, Shaw A, Hoang T: Coordinate secretion of interleukin-1 beta and granulocyte-macrophage colony-stimulating factor by the blast cells of acute myeloblastic leukemia: Role of interleukin-1 as an endogenous inducer. Blood 76:1481, 1990

16. Balkwill F, Osborne R, Burke F, Naylor S, Talbot D, Durbin H, Tavernier J, Fiers-W: Evidence for tumor necrosis factor/cachectin production in cancer. Lancet 2:1229, 1987

17. Naumovski L, Utz PJ, Bergstrom SK, Morgan R, Molina A, Toole JJ, Glader BE, McFall P, Weiss LM, Warnke R, Smith SD: SUP-HD1: A new Hodgkin's disease-derived cell line with lymphoid features produces interferon-gamma. Blood 74:2733, 1989

18. Kremer JP, Reisbach G, Nerl C, Dormer P: B-cell chronic lymphocytic leukemia cells express and release transforming growth factor-beta. Br J Haematol 80:480 1992

19. Means RT: Pathogenesis of the anemia of chronic disease: A cytokine-mediated anemia. Stem Cells 13:32, 1995

20. Jelkmann W, Pagel H, Wolff M, Fandrey J: Monokines inhibiting erythropoietin production in human hepatoma cultures and isolated perfused rat kidneys. Life Sci 50:301, 1991

21. Faquin WC, Schneider TJ, Goldberg MA: Effect of inflammatory cytokines on hypoxia-induced erythropoietin production. Blood 79: 1987, 1992

22. Rusten LS, Jacobsen SEW: Tumor necrosis factor (TNF)- $\alpha$ directly inhibits human erythropoiesis in vitro: Role of p55 and p75 TNF receptors. Blood 85:989, 1995

23. Johnson CS, Keckler DJ, Topper MI, Braunschweiger PG, Furmanski P: In vivo hematopoietic effect of recombinant interleukin- $1 \alpha$ in mice: Stimulation of granulocytic, monocytic, megakaryocytic, and early erythroid progenitors; suppression of late stage erythropoiesis, and reversal of erythroid suppression with erythropoietin. Blood 73:678, 1989

24. Mamus SW, Beck-Schroeder SK, Zanjani ED: Suppression of normal human erythropoiesis by gamma interferon in vitro: Role of monocytes and T-lymphocytes. J Clin Invest 75:1496, 1985

25. Miller KL, Carlino JA, Ogawa Y, Avis PD, Carroll KG: Alterations in erythropoiesis in TGF-beta 1-treated mice. Exp Hematol 20:951, 1992

26. Broxmeyer HE, Sherry B, Cooper S, Lu L, Maze R, Beckmann R, Cerami A, Ralph P: Comparative analysis of the suppressive effects of the human macrophage inflammatory protein family of cytokines (chemokines) on proliferation of myeloid progenitor cells. J Immunol 150:3448, 1993

27. Cooper S, Mantel C, Broxmeyer HE: Myelosuppressive effects in vivo with very low dosages of monomeric recombinant murine macrophage inflammatory protein-1 $\alpha$. Exp Hematol 22:186, 1994

28. Glaspy J, Bukowski R, Steinberg D, Taylor C, Tchekmedyian S, Vadhan-Raj S: Impact of therapy with epoetin alfa on clinical outcomes in patients with nonmyeloid malignancies during cancer chemotherapy in community oncology practice. J Clin Oncol 15:1218, 1997

29. Cascinu S, Fedeli A, Del Ferro E, Luzi Fedeli S, Catalano G: Recombinant human erythropoietin treatment in cisplatin-associated anemia: A randomized, double-blind trial with placebo. J Clin Oncol 12:1058, 1994

30. Henry D, Abels R, Larholt K: Prediction of response to recombinant human erythropoietin ( $\mathrm{r}-\mathrm{HuEPO})$ therapy in cancer patients. Blood 85:1676, 1995

31. Beck MN, Beck D: Recombinant erythropoietin in acute chemotherapy-induced anemia of children with cancer. Med Pediatr Oncol 25:17, 1995

32. Porter JC, Leahey A, Polise K, Bunin G, Manno CS: Recombinant human erythropoietin reduces the needs for erythrocyte and platelet transfusions in pediatric patients with sarcoma: A randomized, double-blind, placebo-controlled trial. J Pediatr 129:656, 1996

33. Teicher BA, Kakeji Y, Rice G, Singer J: Lisofylline (LSF) accelerates hematopoietic recovery and enhances tumor response after high dose chemotherapy. Blood 88:346a, 1996 (abstr) 